Editorial

\title{
The Biomarker Armamentarium for Heart Failure
}

\author{
Kompella S. S. Sai Baba ${ }^{1}$ Mohammed Noorjahan ${ }^{1}$ \\ 1 Department of Biochemistry, Nizam's Institute of Medical Sciences, \\ Punjagutta, Hyderabad, Telangana, India \\ Indian J Cardiovasc Dis Women-WINCARS 2017;2:4-6.
}

Heart failure (HF) is a syndrome characterized by inability of the heart to meet the body's circulatory demands. It is a growing health issue worldwide, and the traditional evaluation methods based on history, physical examination, and chest X-ray can be limited in correctly diagnosing HF. The use of B-type natriuretic peptide (BNP) and its biologically inert, aminoterminal propeptide counterpart ( $\mathrm{N}$-terminal pro-B-type natriuretic peptide [NT-proBNP]) has revolutionized the evaluation and management of patients with HF.

With large number of cardiac biomarkers available, knowledge of the wide range of physiologic and pathologic factors that affect concentrations of these cardiac biomarkers helps us to better understand the results gained from their testing. Despite significant overlaps, cardiac biomarkers can be loosely arranged into the following categories: (1) myocardial insult, (2) neurohormonal activation, (3) remodeling, and (4) comorbidities (-Table $\mathbf{1}$ ). ${ }^{1}$

A critical look at this armamentarium throws up some molecules that are most investigated and becoming popular biomarkers.

$B N P$ and NT-proBNP, are well validated and established in their use and are considered the benchmarks against which other biomarkers are compared. Whereas BNP is believed to be removed quickly from circulation ( $0.5-22$ minutes) by both NP receptor endocytosis and endopeptidase enzymatic degradation, NT-proBNP is cleared from the plasma largely by renal excretion, and thus it has slower fluctuations in circulating concentrations with longer half-life of 60 to 120 minutes. In general, BNP and NT-proBNP values are reasonably correlated, and either can be used as long as their respective absolute values and cut points are not used interchangeably. ${ }^{2}$ Beyond $\mathrm{HF}$, several cardiopulmonary disorders are associated with elevated BNP or NT-proBNP values: acute coronary syndrome, valvular heart disease, myocarditis, hypertrophic cardiomyopathy, atrial fibrillation or flutter, cardiotoxic drugs, and right ventricular dysfunction with significant pulmonary disease. Other conditions associated with higher BNP or NT-proBNP levels may be related to some comorbidities like old age, renal failure, stroke and critical illness, and high output states. Also, use of neprilysin inhibitors leads to pharmacologic raising of

Address for correspondence DOI https://doi.org/

Kompella S. S. Sai Baba, MD, DNB, $10.1055 /$ s-0037-1606850.

Department of Biochemistry,

Nizam's Institute of Medical

Sciences, Punjagutta, Hyderabad,

Telangana 500082, India

(e-mail: ksssaibaba@gmail.com).
BNP values, but these drugs do not affect NT-proBNP levels. Some conditions like HF with preserved ejection fraction (HFpEF) and obesity are associated with lower than expected NP levels. ${ }^{1}$

Atrial natriuretic peptide (ANP) is slightly less consistent as a diagnostic marker than BNP due to its rapid clearance; hence the stable midregional fragment of proANP (MR-proANP) has been used as a robust surrogate marker. ${ }^{2}$ Similar is the case with adrenomedullin (ADM) that is a $52 \mathrm{AA}$ peptide thought to be upregulated due to increased volume. ST2 is part of theinterluekin-1 (IL-1) receptor family. The ligand of ST2 (IL-33) is involved in reducing fibrosis and hypertrophy in mechanical strain. The low intraindividual biological variation of SST2 offers a significant advantage. In patients with $\mathrm{HF}$, an increase of ST2 during a 2-week period was an independent predictor of subsequent death or the need for cardiac transplantation. A combination of ST2 and NT-proBNP might synergistically increase their prediction abilities. ${ }^{3}$

Galectin-3 is another promising molecule and appears to be an early marker of potential myocyte dysfunction as it is overexpressed before the transition to overt HF. The DEAL-HF study has concluded that galectin-3 is an important predictor of mortality risk when adjusted for sex, age, HF severity, and renal dysfunction, thus being a prognostic marker. ${ }^{4}$ Growth differentiation factor 15 (GDF-15), a member of the transforming growth factor $\beta$ (TGF- $\beta$ ) superfamily, was found to be helpful by Wang et al in differentiating reduced from preserved LVEF ADHF. ${ }^{5}$ It is, however, nonspecific, with high levels also present in severe liver disease, pregnancy, and certain cancers. ${ }^{6}$

High-sensitivity troponin (Hs-cTnT) elevation was demonstrated by Latini et al in $90 \%$ of chronic HF patients with a $35.6 \%$ associated mortality risk ( $p<0.0001$ ). Tsutamoto et al demonstrated that elevations in NT-proBNP $(>627 \mathrm{pg} / \mathrm{mL})$ and Hs-cTnI $(>0.03 \mathrm{ng} / \mathrm{mL})$ showed the highest risk of mortality $(p<0.0001)$. Neutrophil gelatinase-associated lipocalin (NGAL) seems to have a role as a biomarker in cases of acute HF. In the (OPTIMAAL [Optimal Trial in Myocardial Infarction with the Angiotensin II Antagonist Losartan]) study done by Dickstein et al in patients with acute HF

Copyright (c) 2017 Women in Cardiology License terms and Related Sciences

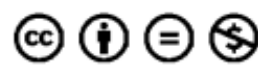


Table 1 Biomarkers of heart failure

\begin{tabular}{|c|c|c|c|}
\hline Myocardial insult & Neurohormonal activation & Remodeling & Comorbidities \\
\hline $\begin{array}{l}\text { Myocardial stretch } \\
\text { - NT-proBNP, BNP, } \\
\text { MR-proANP } \\
\text { - Myocardial injury } \\
\text { - Troponin T \& I, myosin } \\
\text { light-chain I, heart-type } \\
\text { fatty-acid protein, CKMB } \\
\text { Oxidative stress } \\
\text { - Myeloperoxidase, uric } \\
\text { acid, oxidized LDL, } \\
\text { urinary biopyrrins, } \\
\text { urinary and plasma } \\
\text { - Isoprostanes, plasma } \\
\text { malondialdehyde }\end{array}$ & $\begin{array}{l}\text { Renin angiotensin system } \\
\text { - Renin, angiotensin, } \\
\text { aldosterone } \\
\text { Sympathic nervous system } \\
\text { - Norepinephrine, } \\
\text { chromogranin A, } \\
\text { MR-proADM } \\
\text { Arginine vasopressin system } \\
\text { - Arginine vasopressin, } \\
\text { copeptin } \\
\text { Endothelins } \\
\text { - ET-1, big pro-ET-1 }\end{array}$ & $\begin{array}{l}\text { Inflammation } \\
\text { • CRP, TNF- } \alpha \text {, Fas, inter- } \\
\text { leukin, osteoprotegerin, } \\
\text { adiponectin } \\
\text { Hypertrophy/fibrosis } \\
\text { - MMPs, sST2, Galectin-3, } \\
\text { collagen propeptides } \\
\text { Apoptosis } \\
\text { - GDF-15 } \\
\text { Miscellaneous } \\
\text { - MicroRNA, quiescin Q6, } \\
\text { VEGFR-1 }\end{array}$ & $\begin{array}{l}\text { Renal biomarkers } \\
\text { - Creatinine, BUN, eGFR, } \\
\text { cystatin C, } \beta \text {-trace } \\
\text { protein } \\
\text { Renal injury markers } \\
\text { - NGAL, KIM-1, NAG, } \\
\text { liver-type fatty acid } \\
\text { binding } \\
\text { Protein, IL-18 } \\
\text { Hematologic biomarkers } \\
\text { - Hemoglobin, RDW, iron } \\
\text { deficiency (ferritin, } \\
\text { transferrin sat) } \\
\text { Liver function tests } \\
\text { - Albumin }\end{array}$ \\
\hline
\end{tabular}

Abbreviations: BUN, blood urea nitrogen; CKMB, creatine kinase-MB; CRP, C-reactive protein; eGFR, estimated glomerular rate; GDF-15; growth differentiation factor 15; LDL, low-density lipoprotein; MR-proASM, midregional pro-adrenomedullin; MMP, matrix metalloproteinase; MR-proANP, midregional proatrial natriuretic peptide; NGAL, neutrophil gelatinase-associated lipocalin; NT-proBNP, N-terminal pro-B-type natriuretic peptide; RDW, red cell distribution width; TNF, tumor necrosis factor.

following mycoardial infarction (MI), serum NGAL levels were elevated both at baseline and on follow up in patients with the New York Heart Association (NYHA) class III (vs. I/II). The recent GALLANT (NGAL EvaLuation Along with B-type NaTriuretic Peptide) study demonstrated that patients with higher NGAL levels had significantly more HF-related adverse outcomes in 30 days than those with lower levels. ${ }^{6}$

Procalcitonin (PCT) could be a valuable diagnostic marker in patients with undifferentiated dyspnea presenting to the emergency department (ED) to diagnose pneumonia and guide antibiotic treatment. C-reactive protein (CRP) elevation is particularly common in acute HF and can help the diagnosis of infections, which often cause clinical decompensation or coexist with it. ${ }^{6}$ GlycA and $G l y c B$, the newly identified markers of inflammation, have the potential to contribute to better understanding of the inflammatory origins of heart disease and may be used in the future to identify a heart patient's future risk of suffering a heart attack, stroke, or even death. ${ }^{7}$

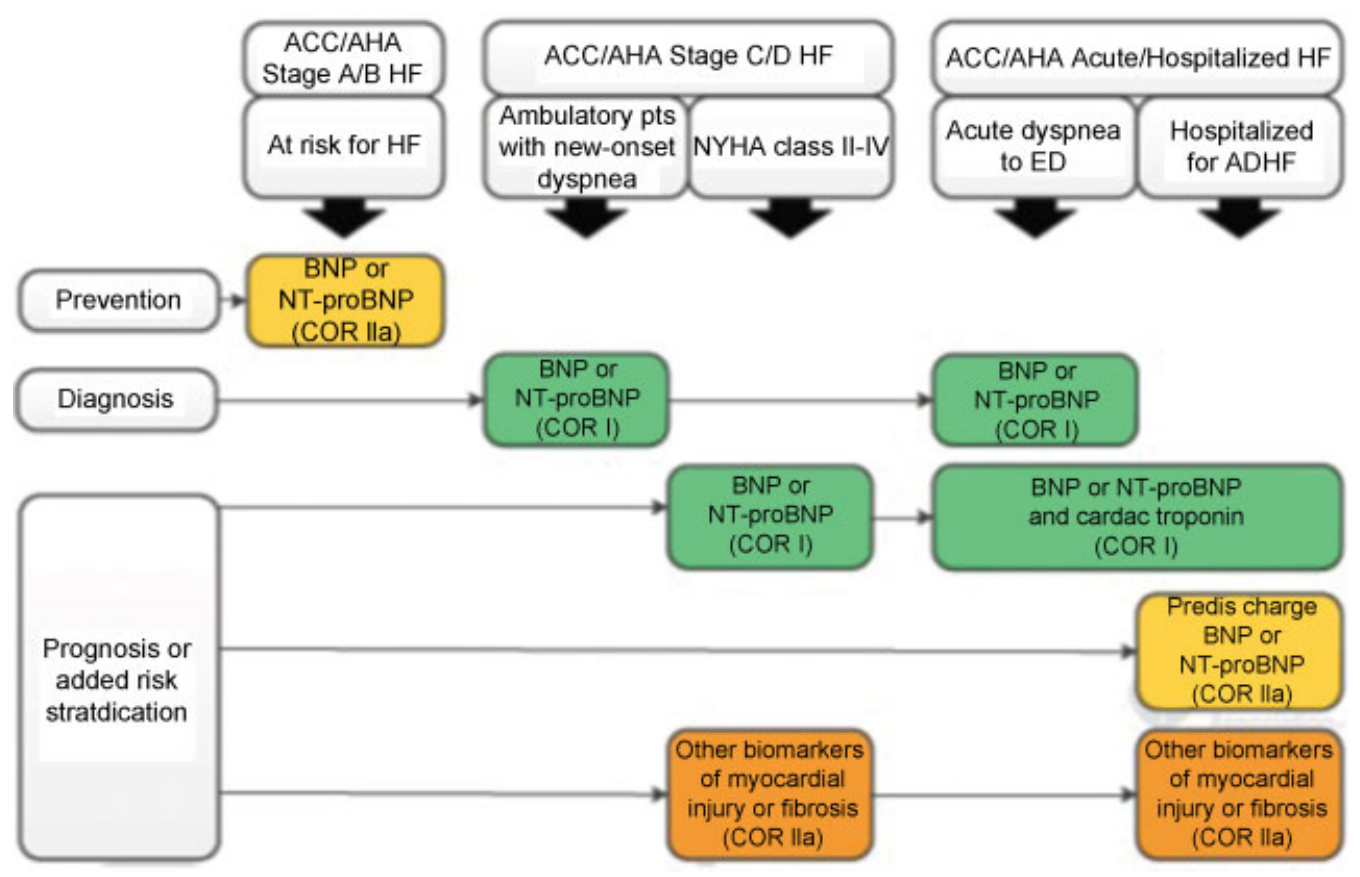

Fig. 1 Biomarkers for use. ${ }^{9}$ Other biomarkers of injury or fibrosis include soluble ST2 receptor, galectin-3, and high-sensitivity troponin. ACC, American College of Cardiology; AHA, American Heart Association; ADHF, acute decompensated heart failure; BNP, B-type natriuretic peptide; COR, class of recommendation; ED, emergency department; HF, heart failure; NT-proBNP, N-terminal pro-B-type natriuretic peptide; NYHA, New York Heart Association; pts, patients. 
Thus, some of these biomarkers are potentially powerful adjuncts to current standards for the diagnosis, prognosis, and treatment of acute and chronic HF. The American College of Cardiology Foundation (ACCF)/American Heart Association (AHA) HF guidelines ( - Fig. 1 ) have given BNP and NT-proBNP a class I recommendation for both diagnosis and prognosis of HF (level of evidence [LOE]: A). The use of these natriuretic peptides for guiding HF management received a class IIa recommendation for chronic HF (LOE: B) and IIb for acute HF (LOE: C). TnT or TnI received class I recommendation (LOE: A) for prognosis and in detection of acute MI as the precipitant of acute HF, while biomarkers of myocardial fibrosis, soluble ST2 (ST2) and galectin-3, received class IIb recommendations (LOE: B for chronic and A for acute HF). ${ }^{8}$

Even though so many biomarkers are there and some of them proved value for diagnosis and prognosis of heart failure, simple and nonexpensive laboratory tests are required for prognostication of HF. This component is heightened by the article published by Mallesh et al in this issue.

Cardiac biomarkers with their objectivity, reproducibility, and accessibility are excellent adjuncts to physical examination and imaging studies in HF diagnosis and risk stratification. Biomarkers not only serve as traditional predictors of prognosis, but they can also help to identify high-risk patients who need closer monitoring and more aggressive therapy. If used in this manner, we will achieve optimal patient care by integrating the results from cardiac biomarker testing along with clinical judgment.

\section{References}

1 Gaggin HK, Januzzi Jame L Jr. Cardiac Biomarkers and Heart Failure. American College of Cardiology. Feb 10, 2015. http:// www.acc.org/latest-in-Cardiology/ articles/ 2015/ 02/09/13/00/ cardiac-biomarkers-and-heart-failure\#sthash

2 Chen WC, Tran KD, Maisel AS. Biomarkers in heart failure. Heart 2010;96(04):314-320

3 Braunwald E. Biomarkers in heart failure. N Engl J Med 2008;358 (20):2148-2159

4 Lok DJ, Van Der Meer P, de la Porte PW, et al. Prognostic value of galectin-3, a novel marker of fibrosis, in patients with chronic heart failure: data from the DEAL-HF study. Clin Res Cardiol 2010; 99(05):323-328

5 Wang F, Guo Y, Yu H, Zheng L, Mi L, Gao W. Growth differentiation factor 15 in different stages of heart failure: potential screening implications. Biomarkers 2010;15(08):671-676

6 Iqbal N, Wentworth B, Choudhary R, et al. Cardiac biomarkers: new tools for heart failure management. Cardiovasc Diagn Ther 2012;2(02):147-164

7 http://www.clinlabint.com/detail/clinicallaboratory/ Two cardiac markers for high risk of heart failure and death

8 Yancy CW, Jessup M, Bozkurt B, et al; American College of Cardiology Foundation; American Heart Association Task Force on Practice Guidelines. 2013 ACCF/AHA guideline for the management of heart failure: a report of the American College of Cardiology Foundation/American Heart Association Task Force on Practice Guidelines. J Am Coll Cardiol 2013;62(16):e147-e239

9 Yancy CW, Jessup M, Bozkurt B, et al. 2017 ACC/AHA/HFSA Focused Update of the 2013 ACCF/AHA Guideline for the Management of Heart Failure: a report of the American College of Cardiology/American Heart Association Task Force on Clinical Practice Guidelines and the Heart Failure Society of America. Circulation 2017;136(06):e137-e161 